\title{
KEMISKINAN MULTIDIMENSI DALAM PERCEPATAN PENCAPAIAN SUSTAINABLE DEVELOMENT GOALS (SDGs) DI RIAU
}

\author{
Syapsan $^{1}$; Dahlan Tampubolon ${ }^{2}$; Sri Endang Kornita ${ }^{3}$ \\ Pusat Studi Sosial Ekonomi, Universitas Riau \\ Kampus Bina Widya Km 12,5 Simpang Baru Pekanbaru \\ E-mail : syapsan@gmail.com \\ diterima: 29/1/2020; direvisi: 5/2/2020; diterbitkan: 26/3/2020
}

\begin{abstract}
The aim of the study is to identify poverty based on a multidimensional poverty approach (MPA) using indicators of Sustainable Development Goals (SDGs). This approach uses a structured method to accelerate the achievement of SDGs in Riau. This method consists of five stages that help identify and implement solutions to accelerate the achievement of SDGs, especially poverty alleviation. The data used are secondary data, especially the medium-term development plan, work plan, and local government budget. The results of the study found that net participation ratio of senior high school education below the national level, although the trend was increasing and there was a decrease in dropout rates. The prevalence of malnutrition toddlers is increasing. In terms of employment there is an increasing trend in the number of labor force, labor force participation rate and the level of open unemployment in Riau Province. Analysis perspective on basic infrastructure owned by the community there is a tendency for decent drinking water to decline. Food consumption (calories) is below the national average even though there is an increasing trend.
\end{abstract}

Keywords: Multidimensional Poverty, SDGs, Enrollment, Malnutrition

\section{PENDAHULUAN}

Kemiskinan menjadi beban bagi negara-negara berkembang terkait upaya mereka untuk meningkatkan statusnya menjadi negara maju. Banyak negara mengumumkan serangkaian Tujuan Pembangunan Milenium atau Millennium Development Goals (MDGs) yang akan dicapai pada tahun 2015 untuk mengurangi setengah jumlah orang di seluruh dunia yang menderita kemiskinan. Menurut laporan pemantauan global, target ini dicapai pada 2010, jauh lebih cepat dari yang diperkirakan (World Bank, 2013).

KTT Bumi Rio de Janeiro pada 2012 mengilhami lahirnya Tujuan Pembangunan Berkelanjutan atau Sustainable Development Goals (SDGs), sebuah model pembangunan berkelanjutan yang dapat membantu menyelesaikan masalah dunia setelah berakhirnya MDGs. SDGs memiliki tujuan yang lebih luas dan merupakan pendekatan berkelanjutan dengan 17 tujuan, 169 target, dan 232 indikator (UN, 2017). Ini kontras dengan MDGs yang hanya berfokus pada delapan tujuan, 18 target, dan 48 indikator (UN, 2000). SDGs dimaksudkan untuk menggantikan MDGs namun, belum dapat diketahui apakah pencapaian SDGs akan melampaui MDGs, tetapi kemungkinan bahwa keberadaan SDGs setidaknya akan menutupi kelemahan MDGs.

Kumar et al. (2016) menyatakan bahwa MDGs dan SDGs adalah dua program di antara banyak program dan menawarkan bukti terbaru tentang keseriusan PBB dalam menangani masalah pembangunan. Program pengentasan kemiskinan untuk semua lapisan masyarakat yang akan mencapai cakupan substansial masyarakat miskin dan rentan di seluruh dunia pada tahun 2030. 
Meskipun agenda utama SDGs adalah untuk mengakhiri kemiskinan, ia juga mengandung sejumlah tujuan yang beragam yang saling berhubungan. Banyak kajian yang dilakukan terhadap SDGs dari berbagai perspektif dan bidang-bidang seperti kesehatan (Proulx et al, 2017), gender (Onditi dan Ondera, 2016), perubahan iklim (Salleh, 2016), hak asasi manusia (Lueddeke, 2015), energi (Weitz et al, 2014) dan banyak lainnya. Sementara itu, Liu et al. (2015) dan Kamruzzaman (2016) adalah contoh dari para peneliti yang secara langsung membahas topik SDG dan kemiskinan. Belum satu pun dari semua kajian tersebut yang mempromosikan Riau sebagai objek utama studinya mereka dan sedikit sekali kajian yang meneliti agenda pengurangan kemiskinan di Indonesia dalam kerangka SDGs.

Provinsi Riau sebagai bagian dari Negara Indonesia ikut berperan melaksanakan delapan tujuan MDGs. Upaya untuk menurunkan angka kemiskinan dan pengentasannya membutuhkan pendekatan yang lebih komprehensif pula. Kemiskinan tidak hanya dilihat dari satu dimensi saja seperti misalnya tingkat konsumsi atau pendapatan, namun dengan pendekatan kemiskinan mulitidimensi. Pendekatan ini bukan hanya berapa jumlah penduduk miskin, juga melainkan mengidentifikasi karakteristik dari kemiskinan yang dialami oleh penduduk. Penghitungan kemiskinan multidimensi ini diukur dengan Indeks Kemiskinan Multidimensi (IKM) atau Multidimensional Poverty Index (MPI), yang dikaji oleh Oxford Poverty and Human Development Initiative (OPHI), Universitas Oxford. Untuk percepatan SDGs Provinsi Riau, maka Multidimensional Poverty Approach (MPA) merupakan pendekatan yang komprehensif dalam kerangka percepatan pengentasan kemiskinan melalui pendekatan pencapaian SDGs di
Provinsi Riau pada tujuan memastikan tidak ada kemiskinan.

\section{TINJAUAN PUSTAKA}

Majelis Umum Perserikatan Bangsa-Bangsa (PBB) pada 2015 mengadopsi 17 tujuan pembangunan berkelanjutan (SDGs). Tujuan dari tujuan ini adalah untuk menetapkan target yang dapat dicapai yang dapat dicapai sebagai agenda 2030 untuk pembangunan berkelanjutan; misalnya, "tujuan dan target akan merangsang tindakan selama 15 tahun ke depan di bidang-bidang yang sangat penting bagi kemanusiaan dan planet ini" (UN, 2015: 5). SDG selanjutnya diuraikan menjadi 169 target, dan saat ini ada sekitar 230 indikator yang telah diusulkan untuk mewujudkan targettarget ini.

Agenda keberlanjutan PBB 2030 juga membantu mengidentifikasi kemungkinan timbal balik di antara SDG yang perlu dipertimbangkan lebih lanjut. Nilsson et al (2016) dan von Stechow et al (2016) melakukan penilaian pendahuluan atas menggunakan pendekatan analisis kesejahteraan. Kajian mereka berfokus pada potensi pertukaran antara tujuan SDGs. Hasilnya menunjukkan tujuan di dalam SDGs saling melengkapi, atau "win-win" serta kemajuannya simultan di antara dua atau lebih tujuan. Pendekatan itu diilustrasikan di sini menambah minat yang berkembang dalam menilai kemungkinan tradeoff dan sinergi dalam mencapai berbagai SDG secara bersamaan.

Costanza et al (2016) menyarankan pilihan tujuan tunggal sistem SDGs sebagai tujuan sistem ekonomi, lingkungan atau sosial. Hal ini harus dilakukan melalui kebijakan yang disebarluaskan, mencakup proses demokratis interaksi pemangku kepentingan dan keterlibatan publik. Mereka mengeksplorasi hubungan antara pendekatan sistem untuk keberlanjutan dan 17 Tujuan Pembangunan 


\section{Jurnal Ilmiah Ekonomi dan Bisnis}

Vol. 17. No.1, Maret 2020 : 24-33

EISSN : $2442-9813$

ISSN : $1829-9822$

Berkelanjutan. Mereka mengadopsi metode standar dari teori pilihan dan kesejahteraan. Hasilnya menunjukkan bahwa adalah mungkin untuk mengukur dampak kesejahteraan dari peningkatan tingkat indikator untuk satu tujuan SDGs dengan mengidentifikasi tradeoff yang terjadi dengan mencapai tujuan lain.

Costanza et al (2016) kemudian melakukan analisis kesejahteraan pendahuluan atas tradeoff ini dengan menggunakan pendekatan yang dikembangkannya. Analisis semacam itu dapat membantu dalam merancang intervensi kebijakan yang tepat untuk mencapai SDGs tertentu, meminimalkan dampak knock-on yang berpotensi negatif pada beberapa tujuan sambil memanfaatkan dampak win-win positif pada SDGs lain.

Jaiyesimi (2016) mengatakan bahwa agenda SDGs tidak hanya perlu memperhatikan penerapan tujuan substantif (Tujuan 1 - 16) dengan cara terintegrasi, namun juga untuk memastikan bahwa implemntasi dalam tujuan 17 dan tujuan-tujuan lainnya sendiri merupakan upaya yang terintegrasi.

\section{METODE PENELITIAN}

Kajian pendekatan kemiskinan multidimensi dalam percepatan pencapaian SDGs di Riau menggunakan metode terstruktur yang terdiri dari lima tahapan yang membantu mengidentifikasi dan menerapkan solusi bagi hambatan untuk mempercepat kemajuan SDGs dalam pengentasan kemiskinan.

Data yang digunakan adalah data sekunder berkenaan dengan rencana jangka menengah, rencana kerja, dan anggaran belanja daerah. Kebijakan dan strategi dikumpulkan dari rencana jangka menengah, program dan kegiatan diambil dari rencana kerja pemerintah daerah. Belanja daerah menggambarkan implementasi kebijakan di dalam kegiatan pengentasan kemiskinan daerah.

Daerah terlebih dahulu

mengidentifikasi prioritas SDGs terkait pengentasan kemiskinan dengan pendekatan kemiskinan multidimensi (Multidiemnsional Poverty Approach atau MPA) di mana direncanakan pencapaian finished target agenda pengentasan kemiskinan pada tahun 2030. Terkait hal tersebut maka komitmen pemerintah daerah sangat diperlukan untuk merealisasikan tujuan dimaksud. Setelah prioritas SDGs dapat diidentifikasi maka lima langkah berikut, yang merupakan metode MPA, dapat diikuti secara berurutan. Proses sistematis ini untuk memastikan bahwa semua tindakan yang relevan telah diidentifikasi, kontribusi lintas sektoral digabungkan dan peran mitra dibentuk.

Tahap1: Identifikasi kemiskinan mengikut multidimensional poverty approach, dengan memasukkan indikatorindikator SDGs.

Tahap 2: Identifikasi intervensi kebijakan strategi dan hambatan implementasi intervensi strategi pengentasan kemiskinan Provinsi Riau. Dalam tahapan ini dilakukan kajian terhadap kesesuaian antara rencana pemerintah daerah dengan prinsip SDGs.

Tahap 3: Pemilihan dan penentuan alternatif strategi pengentasan kemiskinan berbasis MPA dan SDGs

Tahap 4: Rekomendasi strategi pengentasan kemiskinan

Tahap 5 : Rencana implementasi strategi pengentasan kemiskinan Provinsi Riau

\section{HASIL DAN PEMBAHASAN}

Kemiskinan Konsumsi

Kondisi kemiskinan konsumsi digambarkan melalui kondisi capaian 
terhadap 3 indikator utama yaitu Persentase Penduduk Miskin (P0), Indeks Kedalaman Kemiskinan (P1) dan Indeks Keparahan Kemiskinan (P2). Pada bagian ini akan dilakukan identifikasi dan analisis ketiga indikator tersebut terhadap penduduk perkotaan, perdesaan serta akumulasi perkotaan dan perdesaan.

Persentase penduduk miskin perkotaan di Provinsi Riau pada Tahun 2017 lebih rendah dibandingkan Nasional. Posisi relatif persentase penduduk miskin perkotaan di Provinsi Riau Tahun 2017 dibandingkan dengan provinsi lain dan nasional disajikan pada gambar berikut.

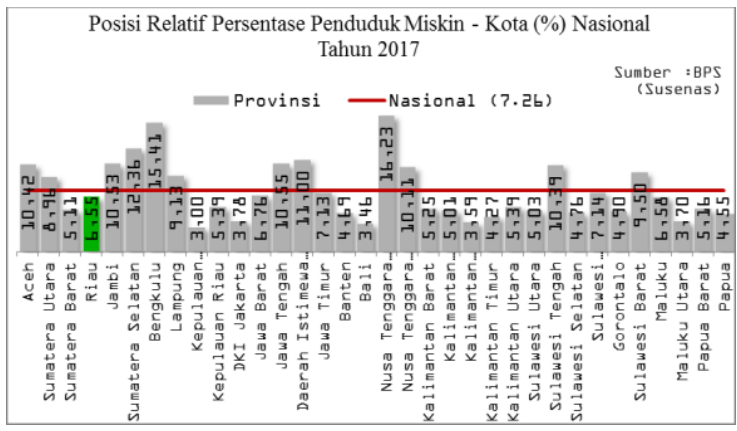

Gambar 1: Posisi Relatif Persentase Penduduk Miskin Perkotaan Provinsi Riau Tahun 2017

Jika dilihat dari sisi perkembangan antar waktu, persentase penduduk miskin perkotaan di Provinsi Riau pada periode 2013 - 2017 cenderung mengalami fluktuasi. Namun demikian terjadi peningkatan pada Tahun 2017 dibandingkan Tahun 2016. Peningkatan yang cukup signifikan terjadi pada Tahun 2015, yang dipicu oleh kenaikan harga barang kebutuhan pokok sebagai akibat dari kenaikan harga bahan bakar minyak. Hal ini juga membutuhkan program-program antikemiskinan global untuk menetapkan konteks yang sesuai untuk menghadapi potensi tantangan untuk memberantas kemiskinan (Kamruzzaman, 2016). Tingkat relevansi perkembangan persentase penduduk miskin perkotaan di Provinsi Riau Tahun 2013 - 2017 terhadap angka nasional menunjukkan tren relevan. Penurunan angka kemiskinan perdesaan nasional diikuti dengan penurunan di tingkat Provinsi Riau. Lebih lanjut dapat dilihat pada Gambar 2.

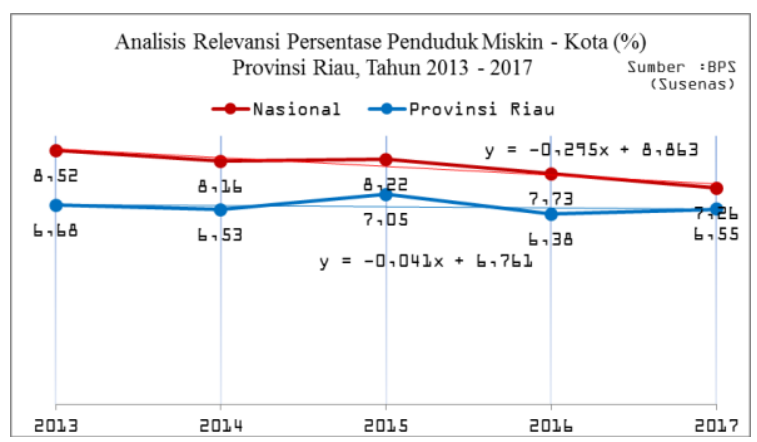

Gambar 2: Relevansi Perkembangan Persentase Penduduk Miskin Perkotaan Provinsi Riau Tahun $2013-2017$

Kedalaman Kemiskinan (P1)

Persoalan kemiskinan bukan hanya sekedar berapa jumlah dan persentase penduduk miskin. Hal lain yang perlu diperhatikan adalah tingkat kedalaman dan keparahan kemiskinan. Indeks Kedalaman Kemiskinan atau Poverty Gap Index/ $P 1$ mengindikasikan rata-rata pengeluaran penduduk miskin cenderung menjauhi atau mendekati garis kemiskinan. Penurunan nilai Indeks Kedalaman Kemiskinan mengindikasikan bahwa rata-rata pengeluaran penduduk miskin cenderung makin mendekati garis kemiskinan (Sirusa BPS).

Posisi relatif Indeks Kedalaman Kemiskinan (P1) Perkotaan di Provinsi Riau berada di bawah angka nasional yaitu sebesar 0.97. Tingkat relevansi perkembangan Indeks P1 Perkotaan antara Provinsi Riau dan Nasional dari Tahun 2013 - 2017 capaian indikatornya terlihat relevan. Hal tersebut dapat dilihat dari penurunan Indeks P1 Perkotaan Nasional juga diikuti oleh penurunan di tingkat Provinsi Riau. Relevansi perkembangan Indeks P1 Perkotaan Provinsi Riau 


\section{Jurnal Ilmiah Ekonomi dan Bisnis}

Vol. 17. No.1, Maret 2020 : 24-33

EISSN : $2442-9813$

ISSN : $1829-9822$

terhadap angka nasional dapat dilihat pada Gambar 3.

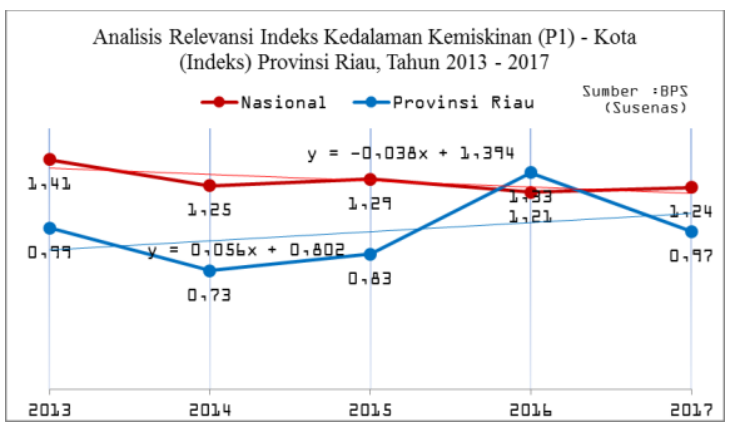

Gambar 3: Relevansi Intervensi Indeks Kedalaman Kemiskinan (P1) Perkotaan Provinsi Riau Terhadap Nasional Tahun 2013 - 2017

Analisis selanjutnya dilakukan terhadap Indeks Kedalaman Kemiskinan (P1) Perdesaan. posisi relatif Indeks P1 Perdesaan di Provinsi Riau berada di bawah angka nasional sebesar 0.95 . Indeks P1 Perdesaan tertinggi berada di Provinsi Papua Barat sebesar 11.81.

Keparahan Kemiskinan

Tingkat efektivitas intervensi Indeks P2 di Provinsi Riau Tahun 2013 - 2017 terlihat tidak efektif. Hal ini ditandai dengan tren peningkatan Indeks P2 Provinsi Riau meski tidak signifikan. Hal ini mengindikasikan bahwa kebijakan penanggulangan kemiskinan belum efektif mengintervensi penurunan Indeks P2. Selengkapnya mengenai efektivitas intervensi Indeks P2 Provinsi Riau Tahun 2013 - 2017 dapat dilihat melalui analisis trendline pada Gambar 4.

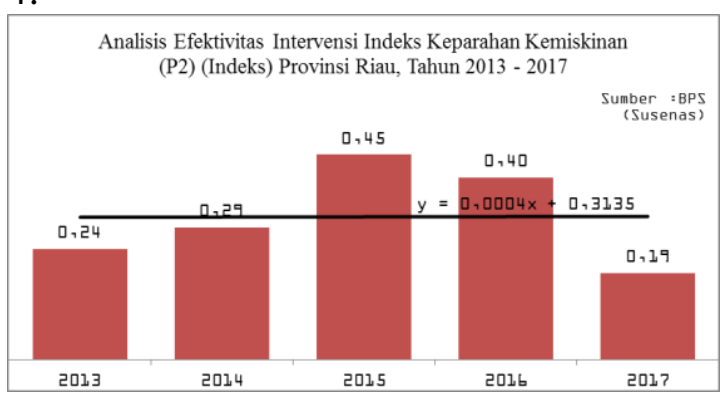

Gambar 4:Efektivitas Intervensi Indeks

Keparahan Kemiskinan (P2) Provinsi Riau Tahun 2013 - 2017
Tingkat relevansi perkembangan Indeks P2 antara Provinsi Riau dan Nasional secara keseluruhan dari Tahun 2013 - 2017 capaian indikatornya terlihat tidak relevan. Hal tersebut dapat dilihat dari penurunan Indeks P2 Nasional yang tidak diikuti oleh penurunan di tingkat Provinsi Riau. Melalui analisis trendline, Indeks P2 Provinsi Riau cenderung meningkat meski tidak signifikan. Relevansi perkembangan Indeks P2 Provinsi Riau terhadap angka nasional dapat dilihat pada gambar berikut.

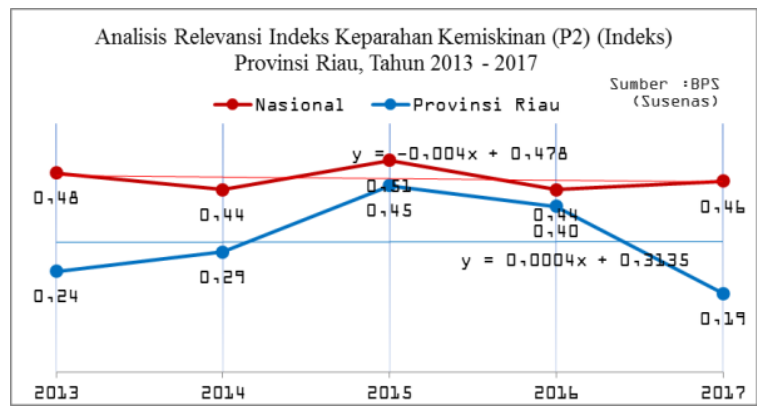

Gambar 5: Relevansi Perkembangan Indeks Keparahan Kemiskinan (P2)

Provinsi Riau Tahun 2013 - 2017

Shaikh (2016) mengemukakan program-program pilantrofi seperti zakat berdampak signifikan terhadap penurunan kedalaman kemiskinan. Shaikh dan Ismail (2017) menjelaskan peran penting zakat di dalam pencapaian SDGs terkait kemiskinan, kelapanan kesejahteraan dan ketimpangan pendapatan.

Kondisi P0, P1 dan P2 merupakan indikator yang saling melengkapi untuk memotret kondisi kemiskinan konsumsi di suatu wilayah. Berdasarkan hasil analisis terhadap indikator kemiskinan konsumsi di atas, maka dapat dilakukan rekapitulasi analisis untuk melihat gambaran secara utuh kondisi kemiskinan konsumsi di Provinsi Riau. Hal ini akan menjadi bahan rujukan dan pertimbangan dalam menentukan fokus permasalahan yang ada di Provinsi Riau untuk kemudian dilakukan perumusan strategi yang efektif. 
Tabel 1: Rekapitulasi Analisis Kondisi Kemiskinan Konsumsi di Provinsi Riau

\begin{tabular}{|c|c|c|c|c|c|}
\hline \multirow[b]{2}{*}{ No } & \multirow[b]{2}{*}{ INDIKATOR } & \multicolumn{4}{|c|}{ PERSPEKTIF ANALISIS } \\
\hline & & $\begin{array}{l}\text { Posisi } \\
\text { Relatif }\end{array}$ & $\begin{array}{l}\text { Perkemb. } \\
\text { Antar } \\
\text { Waktu }\end{array}$ & Efektivitas & Relevansi \\
\hline 1. & $\begin{array}{l}\text { Persentase } \\
\text { Penduduk } \\
\text { Miskin (P0) } \\
\text { Perkotaan }\end{array}$ & $\begin{array}{l}\text { Di } \\
\text { Bawah } \\
\text { Rata - } \\
\text { Rata } \\
\text { Nasional }\end{array}$ & $\begin{array}{l}\text { Fluktuatif; } \\
\text { Meningkat }\end{array}$ & Efektif & $\begin{array}{l}\text { Relevan } \\
\text { Dengan } \\
\text { Nasional }\end{array}$ \\
\hline & $\begin{array}{l}\text { Persentase } \\
\text { Penduduk } \\
\text { Miskin (P0) } \\
\text { Perdesaan }\end{array}$ & $\begin{array}{l}\text { Di } \\
\text { Bawah } \\
\text { Rata - } \\
\text { Rata } \\
\text { Nasional }\end{array}$ & $\begin{array}{l}\text { Fluktuatif; } \\
\text { Menurun }\end{array}$ & Efektif & $\begin{array}{l}\text { Relevan } \\
\text { Dengan } \\
\text { Nasional }\end{array}$ \\
\hline & $\begin{array}{l}\text { Persentase } \\
\text { Penduduk } \\
\text { Miskin (P0) }\end{array}$ & $\begin{array}{l}\text { Di } \\
\text { Bawah } \\
\text { Rata - } \\
\text { Rata } \\
\text { Nasional }\end{array}$ & $\begin{array}{l}\text { Fluktuatif; } \\
\text { Menurun }\end{array}$ & Efektif & $\begin{array}{l}\text { Relevan } \\
\text { Dengan } \\
\text { Nasional }\end{array}$ \\
\hline 2. & $\begin{array}{l}\text { Indeks } \\
\text { Kedalaman } \\
\text { Kemiskinan } \\
(\mathrm{P} 1) \\
\text { Perkotaan }\end{array}$ & $\begin{array}{l}\text { Di } \\
\text { Bawah } \\
\text { Rata - } \\
\text { Rata } \\
\text { Nasional }\end{array}$ & $\begin{array}{l}\text { Fluktuatif; } \\
\text { Menurun }\end{array}$ & $\begin{array}{l}\text { Tidak } \\
\text { Efektif }\end{array}$ & $\begin{array}{l}\text { Tidak } \\
\text { Relevan }\end{array}$ \\
\hline & $\begin{array}{l}\text { Indeks } \\
\text { Kedalaman } \\
\text { Kemiskinan } \\
\text { (P1) } \\
\text { Perdesaan }\end{array}$ & $\begin{array}{l}\text { Di } \\
\text { Bawah } \\
\text { Rata - } \\
\text { Rata } \\
\text { Nasional }\end{array}$ & $\begin{array}{l}\text { Fluktuatif; } \\
\text { Menurun }\end{array}$ & Efektif & $\begin{array}{l}\text { Tidak } \\
\text { Relevan }\end{array}$ \\
\hline & $\begin{array}{l}\text { Indeks } \\
\text { Kedalaman } \\
\text { Kemiskinan } \\
(\mathrm{P} 1)\end{array}$ & $\begin{array}{l}\text { Di } \\
\text { Bawah } \\
\text { Rata - } \\
\text { Rata } \\
\text { Nasional }\end{array}$ & $\begin{array}{l}\text { Fluktuatif; } \\
\text { Menurun }\end{array}$ & Efektif & $\begin{array}{l}\text { Relevan } \\
\text { Dengan } \\
\text { Nasional }\end{array}$ \\
\hline 3. & $\begin{array}{l}\text { Indeks } \\
\text { Keparahan } \\
\text { Kemiskinan } \\
\text { (P2) } \\
\text { Perkotaan }\end{array}$ & $\begin{array}{l}\text { Di } \\
\text { Bawah } \\
\text { Rata - } \\
\text { Rata } \\
\text { Nasional }\end{array}$ & $\begin{array}{l}\text { Fluktuatif; } \\
\text { Menurun }\end{array}$ & $\begin{array}{l}\text { Tidak } \\
\text { Efektif }\end{array}$ & $\begin{array}{l}\text { Tidak } \\
\text { Relevan }\end{array}$ \\
\hline & $\begin{array}{l}\text { Indeks } \\
\text { Keparahan } \\
\text { Kemiskinan } \\
\text { (P2) } \\
\text { Perdesaan }\end{array}$ & $\begin{array}{l}\text { Di } \\
\text { Bawah } \\
\text { Rata - } \\
\text { Rata } \\
\text { Nasional }\end{array}$ & $\begin{array}{l}\text { Fluktuatif; } \\
\text { Menurun }\end{array}$ & Efektif & $\begin{array}{l}\text { Tidak } \\
\text { Relevan }\end{array}$ \\
\hline & $\begin{array}{l}\text { Indeks } \\
\text { Keparahan } \\
\text { Kemiskinan } \\
\text { (P2) }\end{array}$ & $\begin{array}{l}\text { Di } \\
\text { Bawah } \\
\text { Rata - } \\
\text { Rata } \\
\text { Nasional }\end{array}$ & $\begin{array}{l}\text { Fluktuatif; } \\
\text { Menurun }\end{array}$ & $\begin{array}{l}\text { Tidak } \\
\text { Efektif }\end{array}$ & $\begin{array}{l}\text { Tidak } \\
\text { Relevan }\end{array}$ \\
\hline
\end{tabular}

Analisis Kemiskinan Multidimensi

1. Pendidikan

Pendidikan sebagai salah satu dimensi kemiskinan merupakan faktor yang sangat menentukan kondisi kemiskinan di suatu wilayah. Untuk memetakan kondisi pendidikan di Provinsi Riau dapat dilihat dari sisi akses masyarakat terhadap pelayanan pendidikan. Tingkat efektivitas intervensi kebijakan terhadap perkembangan APM SMA/MA di Provinsi Riau dari Tahun 2013 - 2017 tampak efektif. Hal ini ditunjukkan dengan analisis trendline terjadi peningkatan meski tidak terlalu signifikan. Selanjutnya tingkat relevansi perkembangan APM SMA/MA antara Provinsi Riau dan Nasional tampak relevan. Kenaikan di tingkat nasional juga diikuti dengan kenaikan di tingkat Provinsi Riau

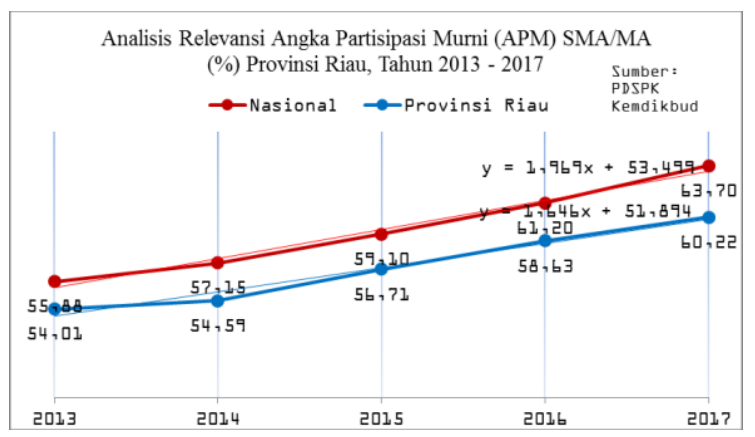

Gambar 6: Relevansi Perkembangan Angka Partisipasi Murni (APM) SMA/MA Provinsi Riau Tahun 2013 - 2017

2. Kesehatan

Berdasarkan Undang - Undang Nomor 36 Tahun 2009 tentang Kesehatan, kesehatan didefinisikan sebagai keadaan sehat, baik secara fisik, mental, spritual maupun sosial yang memungkinkan setiap orang untuk hidup produktif secara sosial dan ekonomis. Sebaliknya seperti vicious cycles, di mana penduduk yang berpendapatan rendah atau miskin cenderung sulit untuk memperoleh akses terhadap pelayanan dasar kesehatan.

Dimensi kesehatan salah satunya dalah prevalensi balita gizi buruk. Perkembangan antar waktu Prevalensi Balita Gizi Buruk di Provinsi Riau dari Tahun 2013 - 2017 menunjukkan tren peningkatan meski sempat terjadi penurunan pada tahun 2014 dan 2015. Pada Tahun 2013, terdapat $1.57 \%$ balita dengan status gizi buruk, kemudian terjadi fluktuasi sampai akhirnya meningkat di Tahun 2017 pada angka 1,64\%.

Selanjutnya analisis dilakukan untuk melihat intervensi kebijakan terhadap perkembangan prevalensi balita gizi buruk di Provinsi Riau. Melalui analisis trendline terhadap perkembangan prevalensi balita gizi buruk di Provinsi Riau pada periode tahun 2013 - 2017 didapati bawa intervensi kebijakan menunjukan indikasi efektif. 


\section{Jurnal Ilmiah Ekonomi dan Bísnis}

Vol. 17. No.1, Maret 2020 : 24-33

EISSN : $2442-9813$

ISSN : $1829-9822$

Perkembangan prevalensi balita gizi buruk di Provinsi Riau tampak tidak relevan dengan perkembangan secara nasional. Hal ini ditunjukkan dengan tren peningkatan di tingkat Provinsi Riau sementara prevalensi balita dengan gizi buruk secara nasional terjadi penurunan.

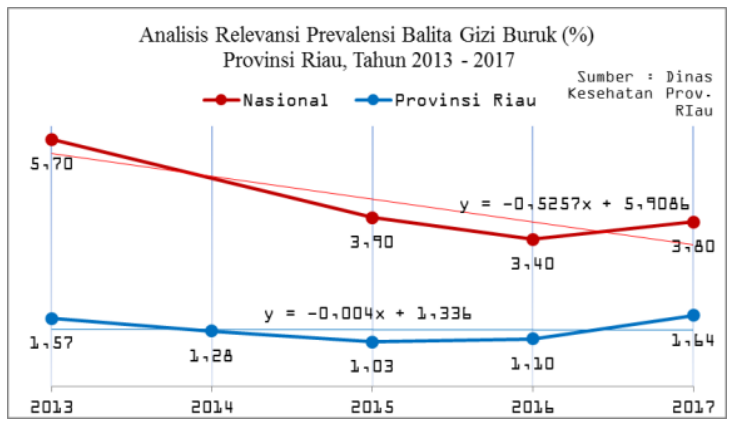

Gambar 7: Relevansi Perkembangan Prevalensi Balita Gizi Buruk Provinsi Riau Tahun 2013 2017

3. Ketenagakerjaan utama

sektor ketenagakerjaan yang akan dianalisis adalah Jumlah Angkatan Kerja, Tingkat Partisipasi Angkatan Kerja dan Tingkat Pengangguran Terbuka. Ketiga indikator ini diharapkan dapat mewakili kondisi ketenagakerjaan di Provinsi Riau sehingga dapat diidentifikasi secara lebih mendalam sebagai bahan pertimbangan penyusunan strategi percepatan penanggulangan kemiskinan.

Angka TPAK yang rendah menunjukkan kecilnya kesempatan kerja yang tersedia bagi penduduk usia kerja. TPAK antara pria dan wanita berbeda. Biasanya TPAK wanita lebih rendah dibandingkan dengan TPAK pria. Hal ini erat kaitannya dengan sistem nilai di masyarakat bahwa pria memikul kewajiban utama untuk mencari nafkah.

Dengan melakukan analisis trendline perkembangan TPAK di Provinsi Riau selama 5 (lima) tahun terakhir yaitu dari 2013 - 2017 dapat dilihat bahwa secara umum terjadi peningkatan tingkat partisipasi. Hal ini menunjukkan efektivitas yang positif antara intervensi kebijakan terhadap peningkatan TPAK meski kenaikannya tidak signifikan. Ramirez (2012) melihat potensi dampak positif dari pertumbuhan ekonomi terhadap lapangan kerja namun berdampak merusak sumber daya alam lingkungan.

Jika dibandingkan antara tren perkembangan TPAK Provinsi Riau dengan Nasional dari Tahun 2013 - 2017 terlihat tidak relevan. Tren TPAK Provinsi Riau menunjukkan kecenderungan peningkatan yang positif meski tidak signifikan. Sedangkan tren TPAK Nasional menunjukkan kecenderungan penurunan. Selengkapnya dapat melihat pada gambar berikut.

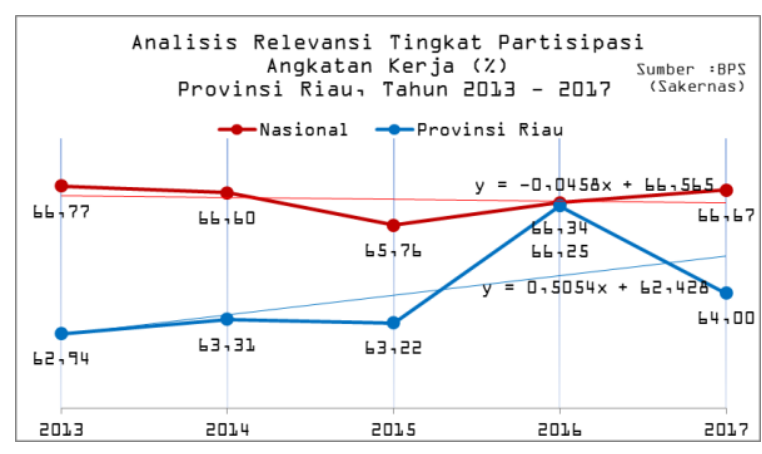

Gambar 8. Relevansi Perkembangan Tingkat Partisipasi Angkatan Kerja (TPAK) Provinsi Riau Tahun 2012 - 2017

4. Infrastruktur Dasar

Pemenuhan infrastruktur dasar merupakan salah satu dimensi dalam upaya penanggulangan kemiskinan yang bersifat multidimensi (Multidimensional Poverty Approach). Dengan pendekatan MPA, infrastruktur dasar dikategorikan sebagai dimensi standar kualitas kehidupan meliputi akses terhadap air minum yang bersih dan layak; akses terhadap sanitasi yang layak dalam rumah tangga; akses terhadap listrik; jenis bahan bakar untuk memasak; jenis lantai rumah dan kepemilikan aset.

Posisi relatif Provinsi Riau terkait proporsi rumah tangga dengan air minum layak adalah sebesar $75,12 \%$ lebih baik 
dari pada rata - rata nasional sebesar 72.04\%. Meski demikian, dari data ini dapat diketahui bahwa hampir 25\% rumah tangga di Provinsi Riau belum mendapatkan sumber air minum layak. Hal ini tentu saja masih perlu mendapat perhatian dari para pemangku kepentingan baik pemerintah, dunia usaha maupun lembaga filantropi untuk dapat bersama - sama merumuskan strategi yang efektif agar semakin banyak rumah tangga yang memperoleh air minum yang layak demi kehidupan yang lebih baik.

Di sisi perkembangan antar waktu, proporsi rumah tangga dengan air minum layak di Provinsi Riau dari Tahun 2013 - 2017 mengalami fluktuasi. Namun demikian posisi tahun 2017 menurun dari tahun 2016 75,49\% menjadi $75,12 \%$. Melalui analisis trendline didapati baha intervensi kebijakan selama Tahun 2013 - 2017 menunjukkan efektivitas yang positif terhadap peningkatan proporsi rumah tangga dengan air minum layak meski tidak signifikan. Hal ini ditunjukkan dengan kecenderungan peningkatan selama 5 tahun terakhir. Terhadap kecenderungan yang tidak signifikan ini perlu dilakukan terobosan kebijakan yang efektif agar semakin banyak rumah tangga di Provinsi Riau yang mendapatkan akses air minum layak.

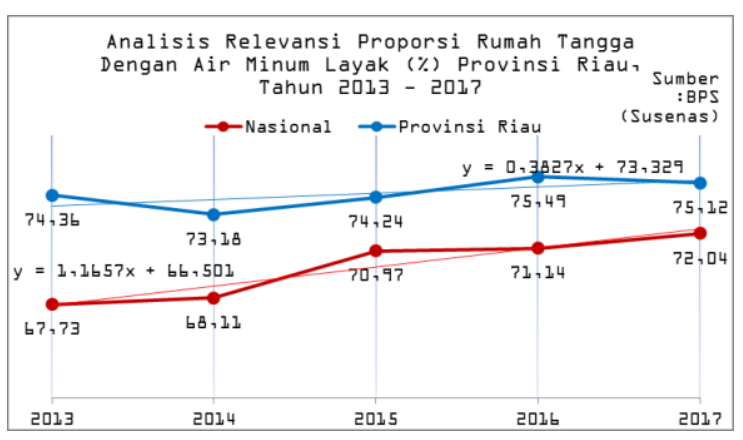

Gambar 9: Relevansi Perkembangan Proporsi Rumah Tangga Dengan Air Minum Layak Provinsi Riau Tahun 2013 - 2017
5. Ketahanan Pangan

Tiga pilar dalam ketahanan pangan yang terdapat dalam definisi tersebut adalah ketersediaan (availability), keterjangkauan (accessibility) baik secara fisik maupun ekonomi, dan stabilitas (stability) yang harus tersedia dan terjangkau setiap saat dan setiap tempat. Apabila ketiga pilar ketahanan pangan terpenuhi, maka masyarakat atau rumah tangga tersebut mampu memenuhi ketahanan pangannya masing-masing (bulog.go.id, 2018).

Posisi relatif indikator rata - rata konsumsi kalori per kapita sehari Provinsi Riau adalah 2.112,58 kkal, masih berada di bawah rata - rata nasional yaitu 2.152,64 kkal. Namun demikian, rata rata penduduk Provinsi Riau telah memenuhi standar minimal kebutuhan kalori harian yang dianjurkan pemerintah yaitu 2.100 kkal. Selengkapnya mengenai posisi relatif konsumsi kalori Provinsi Riau terhadap provinsi lain dan rata - rata nasional dapat merujuk pada gambar berikut.

Perkembangan antar waktu rata rata konsumsi kalori per kapita sehari di Provinsi Riau dari Tahun 2013 - 2017 tampak fluktuatif. Namun demikian posisi tahun 2017 lebih baik dibanding tahun 2016. Nilai rata - rata ini sedikit berada di atas angka kebutuhan minimum yang ditetapkan oleh BPS yaitu 2.100 kkal. Pada Tahun 2017 rata - rata konsumsi kalori penduduk Provinsi Riau adalah 2.112,58 kkal per kapita per hari. Tren peningkatan rata - rata konsumsi kalori per kapita sehari Provinsi Riau Tahun 2013 - 2017 tampak relevan dengan peningkatan rata - rata nasional. Hal ini menjadi indikasi positif bagi upaya peningkatan kesejahteraan penduduk di Provinsi Riau. 


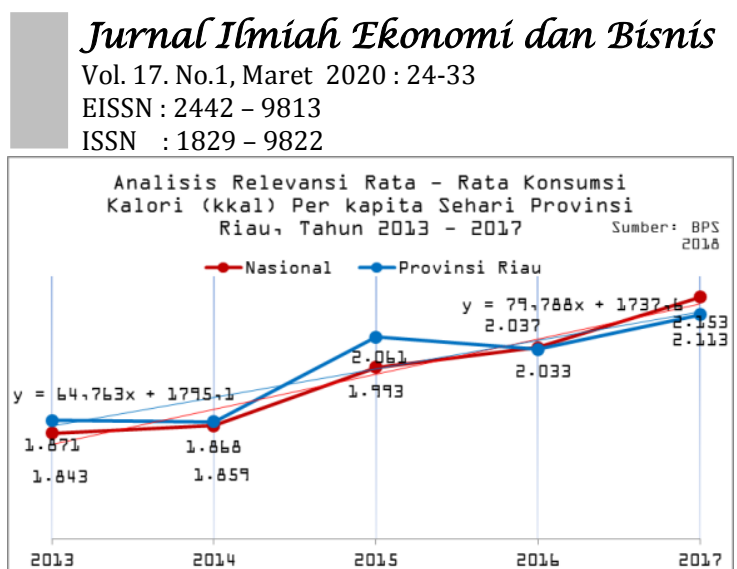

Gambar 5.71. Relevansi Perkembangan Rata Rata Konsumsi Kalori (kkal) Per kapita Sehari Provinsi Riau Tahun 2013 - 2017

\section{KESIMPULAN DAN SARAN}

Hasil analisis pendekatan kemiskinan multidimensi mendapati: Untuk jenjang SLTA, APM masih dibawah nasional, trennya meningkat dengan adanya penurunan angka putus sekolah. Prevalensi balita gizi buruk meningkat. Dari sisi ketenagakerjaan ada tren meningkat dalam jumlah angkatan kerja, tingkat partisipasi angkatan kerja (TPAK), dan tingkat pengangguran terbuka di Provinsi Riau. Perspektif analisis atas infrastruktur dasar yang dimiliki masyarakat ada kecenderungan air minum layak menurun. Konsumsi pangan (kalori) masih di bawah rata-rata nasional walaupun ada kecenderungan meningkat.

Pembangunan inklusif, pertumbuhan ekonomi yang stagnan berujung pada peningkatan angka kemiskinan Pertumbuhan harus mampu menciptakan lapangan kerja produktif dalam jumlah besar. Selanjutnya, diharapkan terdapat multiplier effect pada peningkatan pendapatan mayoritas penduduk, peningkatan taraf hidup, danpengurangan angka kemiskinan. Conditional Cash Transfers (CCT) berupa Program Keluarga Harapan sosial didorong untuk memiliki akses dan memanfaatkan pelayanan sosial dasar kesehatan, pendidikan, pangan dan gizi, perawatan, dan pendampingan.

\section{DAFTAR PUSTAKA}

Barbier, E.B. dan J.C. Burgess (2017). The Sustainable Development Goals and the systems approach to sustainability. Economics 11 (2017-28): 1-22.

Costanza, R., L. Daly, L. Fioramonti, E. Giovannini, I. Kubiszewski, L.F. Mortensen, K.E. Pickett, K.V. Ragnarsdottir, R. De Vogli, R. Wilkinson, (2016). Modelling and measuring sustainable wellbeing in connection with the UN Sustainable Development Goals. Ecological Economics 130: 350355

Jaiyesimi, R. (2016). The Challenge of Implementing the Sustainable Development Goals in Africa: The Way Forward. African Journal of Reproductive Health September 2016 (Special Edition on SDGs); 20(3): 13-18

Kamruzzaman, P. (2016.) A Critical Note on Poverty Eradication Target of Sustainable Development Goals. European Journal of Sustainable Development, 5(2), 87-110.

Kumar, S. N. Kumar dan S. Vivekadhish (2016). Millennium Development Goals (MDGS) to Sustainable Development Goals (SDGS): Addressing Unfinished Agenda and Strengthening Sustainable Development and Partnership. Indian J Community Med 4, 1-4

Liu, Q.Q., M. Yu., dan X.L. Wang. (2015). Poverty reduction within the framework of SDGs and Post-2015 Development Agenda. Advance in Climate Changes Research (6), 67-73.

Lueddeke, G. (2015). Towards an Integrative Post-2015 Sustainable 
Development Goal Framework: Focusing on Global JusticePeace, Security and Basic Human Rights. SEEJPH. [Online] [Diakses 16 Mei 2019]

Nilsson, M., D. Griggs dan M. Visbeck (2016). Map the Interactions between Sustainable Development Goals. Nature 534:320-322.

Onditi, F., dan Odera, J. (2016). Gender Equality as a Means to Women ${ }^{\text {ee }}$ Empowerment? Consensus, Challenges and Prospects for Post-2015 Development Agenda in Africa. African Geographical Review 36(2), 146-167

Proulx, K., Ruckert, A., dan Labonté, R. (2017). Canadaes Flagship Development Priority: Maternal, Newborn and Child Health $(\mathrm{MNCH})$ and the Sustainable Development Goals (SDGs). Canadian Journal of Development Studies, 38(1), 3953.

Ramirez, G. A. (2012). Sustainable development: paradoxes, misunderstandings and learning organizations. The Learning Organization 19(1), 58-76.

Salleh, A. (2016). Climate, Water, and Livelihood Skills: A PostDevelopment Reading of the SDGs. Globalizations, 13(6), 952-959.

Shaikh, S. A. (2016). Zakāt Collectible in OIC Countries for Poverty Alleviation: A Primer on Empirical Estimation. International Journal of Zakat, 1(1), $17-35$.

Shaikh, S.A. dan A.G. Ismail (2017). Role of Zakat in Sustainable Development Goals.
International Journal of Zakat $1(2), 1-9$

United Nations (2000). Goals, Targets, and Indicators. United Nations. [online] [Diakses 16 Mei 2019].

United Nations (2017). Revised List of global Sustainable Development Goal indicators. United Nations. [online] [Diakses 16 Mei 2019].

United Nations (UN) (2015). Transforming Our World: The 2030 Agenda for Sustainable Development.United Nations, New York

von Stechow, C., J.C. Minx, K. Riahi, J. Jewell, D.L. McCollum, M.W. Callaghan, C. Bertram, G. Luderer dan G. Baiocchi (2016). 2C and SDGs: united they stand, divided they fall? Environmental Research Letters 11 (3).

Weitz, N., Nilsson, M. dan Davis M. (2014). A Nexus Approach to the Post-2015 Agenda: Formulating Integrated Water, Energy, and Food SDGs. SAIS Review of International Affairs, 34(2), 37-50

World Bank. (2013). Rural-Urban Dynamics and the Millennium Development Goals. World Bank. [online] [Diakses 16 Mei 2019]. 